\title{
Transition to International Energy Economic Equivalent of Future Economy
}

\author{
Evgeniy Bryndin \\ Research Department, Research Center Natural Informatic, Novosibirsk, Russia
}

Email address:

bryndin15@yandex.ru

\section{To cite this article:}

Evgeniy Bryndin. Transition to International Energy Economic Equivalent of Future Economy. International Journal of Economy, Energy and Environment. Vol. 6, No. 5, 2021, pp. 86-90. doi: 10.11648/j.ijeee.20210605.11

Received: August 22, 2021; Accepted: September 2, 2021; Published: September 8, 2021

\begin{abstract}
Energy resources are key to the economy. Firstly, any processes in the production sector are associated with energy consumption. Energy costs permeate all areas of material production, are the most important and integral part of both core and working capital. Secondly, energy resources are currently scarce and define the limits of economic development. At present, the issues of improving energy efficiency from the sectors of the economy are given great attention. For the implementation of programs to increase economic efficiency, the development of theoretical provisions and methodological foundations of energy economic assessment of production is of great importance, There is a variation in the energy equivalents per waste of production resources offered by standards for different types of energy. Considering energy issues in economic systems, economic energy is not found in the relevant classifications, but experts consider the allocation of such a category in the theory of economic development to be timely, and this category fully meets all economic indicators. To do this, it is necessary to determine the energy equivalent for each energy source. The article assumes the calculation of energy equivalents expressed by rational numbers. The use of energy equivalents allows you to move to a single measure of energy for all types. A single measure of energy allows you to move to a single international currency for financial and economic international cooperation.
\end{abstract}

Keywords: Types of Energy, Green Equivalent, Single Currency, International Cooperation, BRICS Community

\section{Introduction}

Some economists believe that energy can play the role of money. Indeed, this is something that is absolutely understandable, visible, tangible, can be somehow measured and has an enduring value to which everything can be reduced. No energy anywhere. Therefore, many reformers of the modern monetary system propose to estimate the cost of production by its energy equivalent. You can't print the energy equivalent, you can't emit it. Hence, the Energy Equivalent Stabilizer of the Economic System. The introduction of energy equivalent value does not change the current market system. In this case, the role of money passes to the energy equivalent.

In the understanding of E. Y. Yagelskaya, economic energy is an array of energies that determine the qualitative and quantitative state of the economic system and determine the transformation of its structure by changing the space-time arrangement of the elements of the system [1-2]. That is, the state of the economic system is due to the value of economic energy [3]. On the basis of energy theory "energy of progress" M. Rudenko is formed [4]. In addition, the concepts of energy efficiency coefficient and net useful energy introduced by scientists are of particular importance [5].

American resident Nixon successfully made the transition from the gold standard to petrodollar. Recently, petrodollars have slowly, but still surrender their central positions in the world, stopping to play the role of the main way of calculating between the parties. When petrodollars work for the US economy, it is economically unprofitable for other states. The danger to US petrodollars is already represented by the deals that China has concluded with the UAE, as well as with Brazil, Japan, Australia, Chile. The Russian Federation also intends to use its currency in trade with Iran. The collapse of petrodollar will ensure the complete refusal of oil-producing states to carry out oil operations in this currency.

The economic interests of all states in international 
cooperation can provide a single world economic energy equivalent. The transition to a single world economic energy equivalent can be moved on the basis of a single energy measure for all types of energy. The international platform can be a union of countries, the developing BRICS community [6].

\section{A Single Standard Measure for All Types of Energy}

Energy is considered as action, activity, strength, power. Energy is a single measure of various forms of motion and interaction of matter, a measure of the transition of the movement of matter from one form to another. The introduction of the concept of energy is convenient in that if the physical system is closed, then its energy is stored in this system for a time during which the system will be closed. This statement is called the energy conservation law. Energy, as a substance of a closed system, ensures its functioning for a period of time during which the system will be closed. Systems are organic and inorganic. There are several types of energy: biochemical, electrical, magnetic, gravitational, mechanical, thermal, chemical, nuclear and other types.

The energy of one system can generate the energy of another system according to the law of energy conservation: how much energy of one type was spent, how much energy of another type was received.

The energy is measured with a scalar value. Each type of energy has its own unit of measure. International standard measurement systems have been developed. The physical dimension and the ratio between units are defined. Units of energy measurement in SI system - joule, in GHS system erg. In the LMT physical quantity system, energy types have each their own dimension.

The LMT physical quantity system is a set of units of measurement of various types of energy, formed in accordance with physical principles. Equivalent ratios between units of measure of different types of energy are determined. Equivalent ratios of units of different types of energy are determined experimentally in accordance with the law of energy conservation [7,8]. A disadvantage of the LMT system is the representation of units of different types of energy with approximate decimal numbers. This results in large errors for large quantitative energy values.

A complete system of equivalent unit ratios allows you to enter a single standard unit of energy, regardless of the type of energy. It is proposed to introduce a single standard measure of energy SME. A single standard unit of energy can be erg, or joule, or a new unit beg, as a single measure of various forms of motion of matter.

Equivalent ratios of units of different types of energy through pairs of ratios lead to a single standard unit of measurement of all types of energies. Quantitative values of energy units of various types are usefully represented by rational numbers. This will avoid significant errors for large energy values.

\section{Advantages of a Single Energy Measure}

A single measure of energy expands and unites cooperation. First, working procedures and rules of conduct are clearly regulated and become a clear guide to action.

Secondly, a unified vision and a unified approach to working situations is being formed. Thirdly, a high standard of service quality is ensured.

Fourth, a unified measure of energy is designed to ensure: the development of conscientious competitiveness of products, works, services; production and circulation of innovative and high-tech products.

Fifth, information provided on the basis of a single standard energy measure reduces the problem of information asymmetry.

Sixth, it will give an additional impetus to the development of the economies of states. trade and investment flows will increase.

Seventh, business ties will be strengthened and the wellbeing of citizens will increase. Eighth, a single measure of energy will allow more efficient energy dialogue and the formation of energy education.

Ninth, the need for reasonable use of energy resources, balanced consideration of the interests of various States in modern conditions, a single measure will simplify the approach to issues of international legal regulation.

Ninth, a single measure of energy can serve as a transition to an international unit of account for all types of energy and various products in the form of energy-beg.

In relation to international energy cooperation as an integral part of cooperation in the economic sphere, as well as taking into account the globally integrated nature of the energy industry and the growing interdependence between States in this field, energy is an integrated sphere of cooperation covering both the economic, commercial, scientific, technical, social, environmental and security spheres of States. Energy diplomacy has become the main tool for achieving energy policy goals. The most important task of diplomacy in general is to establish and maintain a sustainable balance of interests between different actors, often with opposing interests. Diplomacy is designed to find a way to reconcile these interests in order to find a balance. This assertion is also true of energy diplomacy, which involves balancing energy demand and supply, transit issues, mutual investment, and harmonization of trade rules. Some environmental issues directly related to energy development have also become global. Among them, the problem of climate ("greenhouse effect") stands out. There has been a steady trend of growing interdependence between energy and environmental components in the economic policies of States. One possible effective solution to this problem is to diversify energy sources and increase the share of renewable energy sources in the global energy mix. The implementation of such an approach allows, on the basis of a single energy measure, to reduce the negative impact on the environment with the involvement of the international organization of 
legislative metrology and the international bureau of measures and weights [9].

The introduction of a single standard energy measure will increase the efficiency of research and development; reduce risks and costs; support the development of new products and markets. The fundamental function of a unified standard energy measure is to increase the pace of technical introduction and development of innovative technological innovations, which will ultimately lead to an improvement in the quality indicators of goods and services sold [10].

\section{Commodity Price Energy Equivalent Factors}

Pricing as a science is very extensive and similar to magic or even sacrament. Thousands or perhaps millions of manufacturers are tormented by the question of how to put a price on a product so that it is bought and bought willingly, and that the manufacturer receives the maximum possible profit from the sale of its product. If the product is known on the market, you need to study the market and find the middle ground of the price that will appeal to customers and suit the producer. What factors to take into account in the price of energy equivalent, if the product is new and it has not yet been on the market.

In a free market, it is very important to correctly determine the value of a product or service, which in most cases is not regulated at the legislative level. The efficiency of trade directly depends on this parameter and, as a result, the economic feasibility of the enterprise. Competition in this area occurs both between manufacturers of the product and between sellers. The business results of the company depend on the correct calculations. This section will briefly discuss pricing as an energy equivalent.

First of all, it is worth understanding the essence of the issue in order to better understand it in the future. This will help to better concentrate on the subject. So, let's get acquainted with the peculiarities of the main question. The pricing system has several main goals that make miscalculation very important for commercial activity. First of all, it covers the costs of manufacturing and selling products and ensuring a level of profit. It should be sufficient for the efficient functioning of production. In addition, it is important to take into account the interchangeability of goods and services presented on the market when calculating prices. There is also a need to address social and environmental concerns.

The next item is to calculate the demand for a product or service. Without defining this measure, you cannot generate an optimal parameter. In addition, it is necessary to calculate possible changes in interest in the product, taking into account external and internal factors.

After marketing, the future costs associated with manufacturing and implementation are analyzed. They are constant and variable. The size of the former does not increase along with the increase in production. The sum of these two figures forms gross costs. They represent the minimum elevation.

Also, when choosing any of the main methods for generating the price of goods from the system, it is important to calculate the cost of products of competitor companies and consumer demand for it. Data on its characteristics and distinguishing features will also be useful. The more information the company's employees have, the more opportunities there are. Using these parameters, the place of the enterprise in the market and its share in German are calculated using specialized online services for monitoring.

In cases where the price of products is determined by the government, the parameters depend on the costs of manufacture and sale. Both external and internal conditions are taken into account. It is important to take them into account and correctly analyze them in order to summarize all the actual costs of production and implementation, and then lay them at the base of prices. Calculate the full cost of the goods and add profit to it. Modern technologies allow you to accurately calculate the necessary energy costs. This ensures stability of market value. It is necessary to take into account all changes in the production process and take into account demand and supply. Thus, it becomes possible to analyze the actual energy costs by factors based on the reasons that led to them. This allows you to constantly monitor the profits, actual costs that arise and the actions that are necessary to reduce them.

According to the amount of energy costs of manufactured goods, the government calculates the cost of a single energy measure and introduces it into circulation for calculating the price of goods. This approach sets real prices for manufactured goods and services and makes them more sustainable [11].

Producers set prices based on market conditions and costs. They are based on a deep analysis of the popularity of a particular product and the size of the existing offer. This category is based on the calculation of the energy costs that occur when a single item is produced. This is used in the manufacture of high-tech products in which many characteristics play a role. Regression analysis is performed to determine the dependence of product value on several basic parameters using equations.

The regression analysis method is used when several technical and economic parameters are significant for a new product, it is compared with a number of products with similar characteristics, and the price ratio for the entire series of products is calculated based on their parameters according to the formula:

$$
\text { Price }=f\left(X 1, X 2, \ldots X_{\mathrm{n}}\right)
$$

where $\mathrm{X}$ is the quantity of one of the commodity parameters.

Based on the above formula can obtain regression equations, from which then choose the most suitable for our conditions:

1. linear equation: $f=a_{0}+\sum a_{i} x_{i}$,

2. power equation: $f=a_{0}+\Pi x_{i}^{\text {ni }}$,

3. parabolic equation: $\mathrm{f}=\mathrm{a}_{0}+\sum \mathrm{a}_{\mathrm{i}} \mathrm{x}_{\mathrm{i}}+\sum \mathrm{b}_{\mathrm{i}} \mathrm{x}_{\mathrm{i}}^{2}$. 
Regression analysis works if the prices of the goods with which the new product is compared have not been obtained using the same method, but have already been adjusted by market conditions. This method is well used when launching new models of cars, cell phones, high-tech equipment for sale.

The approach is also used in the decision-making process to increase profits due to the level of production or to change the assortment of goods. Its essence is in calculating the total cost and summing it with a percentage that corresponds to the company's contribution to increasing the level of final value of products.

The essence of the profitability of investments in establishing such a cost of products as to cover the amount of borrowed funds. In this case, the amount of interest on credit obligations is added to the cost price. Widely used by large companies.

\section{BRICS Transition to International Energy Economic Equivalent}

The BRICS countries are represented by the Russian Federation, Brazil, China, India and the Republic of South Africa. These five unification states are considered the largest world market. Governments of the BRICS countries regulate the defense of the principles of the development of an open economy. The unified BRICS energy currency will make the participants financially stable, guarantee protection from pressure from other states. For example, the trade wars of the United States of America, the sanctions of the European Union have a negative impact on international calculations.

Today, the BRICS association is considered a modern example of how it is possible to build an international economy. There is no monopolist and dictatorship in this association, all decisions are made with full respect for the interests of all states. Citizens of the BRICS countries in number exceed half of the total population of the planet. Almost all residents of the Russian Federation, the Republic of South Africa, China, India and Brazil believe that the association has chosen the right way to create a financial mechanism independent of America and other Western countries. For example, the signing of an agreement on the creation of its own BRICS Bank, the establishment of a single currency.

A single currency can be linked by a single measure of energy. Then the single BRICS currency will be confirmed by real resources, assets. BRICS countries are rich in human, raw materials, natural factors that can easily become a financial instrument. At the same time, economists and financiers believe that after its appearance, the world will be divided into two categories. The progressive category will include the countries included in the BRICS.

A single currency will simplify the conversion process. In the next step, you create an internal payment system. This will attract other countries to BRICS. The quick implementation of the idea will allow accumulating about
$70 \%$ of states in one payment system. Experts believe that the implementation of the project will be a seven-mile step towards the economic prosperity of all states individually and BRICS as a whole. The faster this necessary step is taken, the faster development will go.

Many financial experts believe that the digital currency will be a course towards rapprochement between the BRICS countries. Digital currency, provided by a single measure of energy, can be carried out through various technological systems. With its help, participants will be able to conduct a huge number of operations in a short time with partners, suppliers from China, India, Russia, Brazil, South Africa and other countries [12].

Blockchain technology will help create a system of international payments in many sectors of life and development of states. It has every chance and prospect of uniting global market players, as digital coins are widely used on the planet. Such a financial instrument will allow paying for goods and services anywhere in the world. [13] It will operate in parallel with national currencies, and the exchange rate will be set by the financial market. At the same time, it does not matter at all who will and where to make translations.

The development of a single digital currency for BRICS member countries will require solving many technological, macroeconomic and organizational problems based on a model strategy for introducing digital technologies into the economy [14].

Today, products and products produced by national craftsmen, companies and manufacturers are in great demand [15]. BRICS aims to exchange experience, increase trade, tourist flow, that is, the comprehensive development of the economy of the participating states.

\section{Conclusion}

According to the amount of energy costs of manufactured goods, the government calculates the cost of a single energy measure and introduces it into circulation for calculating the price of goods. This approach sets real prices for manufactured goods and services and makes them more sustainable.

The transition to a single standard unit of measurement of all types of energy will simplify the system of standardization and certification and make it more efficient and unified on an international scale. A single measure of energy, expressed in rational numbers, will give more accurate readings of large amounts of energy. A single measure of energy will expand and unite international cooperation in many areas of activity. The single currency of the BRICS countries, developed on the basis of a single energy measure, can become the world economic equivalent.

The development of an international economic energy equivalent will require interdisciplinary studies of the world community so that energy economic reform is sound, takes into account the difference between simple and complex labor, as well as between mental and physical labor, 
exchange operations based on energy equivalent in information form, determine the energy intensity of mortgage credit or innovation and banking, evaluate all world assets and the state of crisis, etc.

An economy based on energy equivalent will be more open and objective, will not be speculative and will depend on people's preference. The economy will operate on the basis of information digital technologies.

\section{References}

[1] Yagelska K. Epistemology of Economic Development / K. Yagelska // Priorities for the National Economy: a collection of scientific works of Donetsk State University of Management. Donetsk: DonDDU, 2011. - Vol. XII. - P. 148-156.

[2] Yagelska K. Energy and Entropy in the Waves Formation of the Economic System. // International Economic Policy. Special. release in 2 parts. Part 1. - Kyiv: "KNEU named by V. Getman", 2012. - P. 274-280.

[3] E. Y. Yagelskaya, Donetsk National Technical University. THE ESSENCE AND STRUCTURE OF ECONOMIC ENERGY. Economic and management problems. № 8 (24) - 2013.

[4] Rudenko M. Progress Energy / M. Rudenko. - Ternopil: Jura, 2005. $-412 \mathrm{p}$.

[5] Prigogin I. Order Out of Chaos. New Dialogue of Man with Nature / I. Prigogin, I. Stengers. - Moscow: KomKniga 2005. $-312 \mathrm{p}$.

[6] Evgeny Bryndin. BRICS welfare. VII All-Russian Congress "Political Science before the Challenges of Modern Politics." M.: MGIMO. 2015. C. 106-108.
[7] Energy. Energy Units. URL: https://www.calc.ru/Energiya/

[8] Conversion of energy units. URL: https://kalkulator.pro/energy-conversion.html

[9] Evgeniy Bryndin. Development of living floor spaces on the basis of ecological economic and social programs. $J$. Resources and Environmental Economics. V. 1, №.1. 2018. P. $1-8$.

[10] Bryndin E. G. Global Social-Economic Stabilization. Scholar Journal of Applied Sciences and Research, Volume 1: 3. 2018. P. 41-46.

[11] Evgeniy Bryndin. Financial Turnover of Cyclical Economy by Reinvesting in Ecological Production of Its Savings. $J$. Resources and Environmental Economics. Volume 2, №. 1. Singapore: Syncsci Publishing. 2020. Pages: 96-101.

[12] Tkachenko I. Y. Opportunities of supranational regulation of the digital economy in the BRICS countries. The Russian external economic Bulletin, 2018, no. 5, pp. 9-11.

[13] Evgeniy Bryndin. Digital technologies of the industry 4.0. I Chepter 10, C. 201-222, Book: Computer Science Advances: Research and Applications. USA: Nova Science Publisher. 2019. 252 pages.

[14] Evgeny Bryndin. Formation of International Ethical Digital Environment with Smart Artificial Intelligence. Automation, Control and Intelligent Systems. Vol. 9, Issue 1, 2021, pp. 2738 .

[15] Evgeniy Bryndin. Creation of Social Self-sufficient Digital Natural Ecological Economy with Industry 5.0 of Social State. Internet of Things and Cloud Computing. Volume 8, Issue 2. 2020. pp. 17-23. 